\title{
THE
}

6-17-2015

\section{Crustal and Upper Mantle Structure Beneath the Northeastern Tibetan Plateau from Joint Analysis of Receiver Functions and Rayleigh Wave Dispersions}

\author{
Dan Zheng \\ Hongyi Li \\ Yang Shen \\ University of Rhode Island, y.shen@icloud.com \\ Jing Tan \\ Longbin Ouyang
}

See next page for additional authors

Follow this and additional works at: https://digitalcommons.uri.edu/gsofacpubs

Terms of Use

All rights reserved under copyright.

\section{Citation/Publisher Attribution}

Dan Zheng, Hongyi Li, Yang Shen, Jing Tan, Longbin Ouyang and Xinfu Li. (2016). Crustal and upper mantle structure beneath the northeastern Tibetan Plateau from joint analysis of receiver functions and Rayleigh wave dispersions. Geophysical Journal International, 204(1), 583-590.

Available at: http://gji.oxfordjournals.org/content/204/1/583.short

This Article is brought to you for free and open access by the Graduate School of Oceanography at DigitalCommons@URI. It has been accepted for inclusion in Graduate School of Oceanography Faculty Publications by an authorized administrator of DigitalCommons@URI. For more information, please contact digitalcommons-group@uri.edu. 


\section{Authors}

Dan Zheng, Hongyi Li, Yang Shen, Jing Tan, Longbin Ouyang, and Xinfu Lu 


\title{
Crustal and upper mantle structure beneath the northeastern Tibetan Plateau from joint analysis of receiver functions and Rayleigh wave dispersions
}

\author{
Dan Zheng, ${ }^{1,2}$ Hongyi Li, ${ }^{1,2}$ Yang Shen, ${ }^{3}$ Jing Tan, ${ }^{4}$ Longbin Ouyang ${ }^{2}$ and Xinfu $\mathrm{Li}^{2}$ \\ ${ }^{1}$ Key Laboratory of Geo-detection, China University of Geosciences, Ministry of Education, Beijing, China. E-mail: lih@cugb.edu.cn \\ ${ }^{2}$ School of Geophysics and Information Technology, China University of Geosciences, Beijing, China \\ ${ }^{3}$ Graduate School of Oceanography, University of Rhode Island, Kingston, RI, USA \\ ${ }^{4}$ Geological Exploration Technologies Institute of Anhui Province, Hefei, Anhui, China
}

Accepted 2015 October 26. Received 2015 October 26; in original form 2015 June 17

\begin{abstract}
S UMMAR Y
The crustal and upper mantle velocity structure in the northeastern Tibetan Plateau is obtained from joint analysis of receiver functions and Rayleigh wave dispersions. The resulting velocity model reveals a close correlation between the thick $(>60 \mathrm{~km})$ crust and the presence of an intracrustal low-velocity zone beneath the Qiangtang and Songpan-Ganzi terranes as well as the northwestern Qilian orogen. However, the high $V_{\mathrm{p}} / V_{\mathrm{s}}$ ratio of the crust is found only beneath the Qiangtang and Songpan-Ganzi terranes. The crustal low velocity zone does not appear in the west Qinling and southeastern Qilian orogens, which have a relatively thin $(\sim 50 \mathrm{~km})$ crust, indicating that crustal channel flow is not the primary mechanism by which the northeastern Tibetan Plateau grows. A continuous low velocity zone from the mid-to-lower crust down to $160 \mathrm{~km}$ beneath the eastern Kunlun fault suggests an induced local mantle upwelling after partial detachment of the lithosphere.
\end{abstract}

Key words: Body waves; Surface waves and free oscillations; Seismic tomography; Asia.

\section{INTRODUCTION}

The northeastern Tibetan Plateau (NET) is characterized by mountain ranges with a NW-SE strike and surrounded by active thrust and sinistral strike-slip faults - the Altyn Tagh fault, the eastern Kunlun fault, and the Haiyuan fault (Fig. 1). It is a complex, heterogeneous region that has experienced crustal shortening and thickening as well as magmatism (e.g. Tapponnier et al. 2001). North of the Qaidam basin, the Qilian orogen is composed of complicated Early Palaeozoic arcs and has undergone cumulative shortening of $\sim 360 \mathrm{~km}$, with a shortening rate of $13 \mathrm{~mm} \mathrm{yr}^{-1}$ in the northeast direction (Yin \& Harrison 2000). To the south, the strike-slip eastern Kunlun fault, which has experienced a late Quaternary slip rate of $>10 \mathrm{~mm} \mathrm{yr}^{-1}$ in the west to $2 \mathrm{~mm} \mathrm{yr}^{-1}$ in the east, represents a transition zone from a low-relief and high-altitude plateau in the south to a northern active region (Kirby et al. 2007).

A number of models have been proposed to explain the tectonic processes of the Tibetan Plateau. For instance, in the crustal channel flow model, the lower crust of the eastern plateau moves eastward and is diverted into northeast and southeast around the Sichuan basin (Royden et al. 1997; Clark \& Royden 2000). The rigid block model suggests that the subduction is accompanied by extrusion along the left lateral strike-slip faults (Tapponnier et al. 2001). Both models have supporting geophysical observations (e.g. Yao et al. 2008; Li et al. 2009; Bai et al. 2010). A recent study suggests that localized rigid block motion and crustal flow are two reconcilable crustal deformation mechanisms in the eastern Tibetan Plateau, as a combination of the two deformation modes could contribute significantly to the plateau expansion (Liu et al. 2014).

In the NET, research results seem to be more controversial. Previous results of surface wave tomography and receiver functions suggest that the crust and mantle structure in the NET is very heterogeneous (e.g. Bao et al. 2013; Jiang et al. 2014; Li et al. 2014). Magnetotelluric observations found that a finger-like crustal melt penetrates north from the Songpan-Ganzi terrane and weakens the crust beneath the Kunlun Shan (Pape et al. 2012). Ambient noise tomography by Li et al. (2014) showed that the mid-to-lower crustal LVZ thinned out around the eastern Kunlun fault, while Jiang et al. (2014) observed a weak crust in the Qinling Orogen facilitating the northeastern extrusion of the LVZs. Receiver functions near the Qaidam basin showed a south-dipping velocity discontinuity in the upper mantle, which is interpreted as the top of the subducting Eurasia mantle lithosphere (Kind et al. 2002), however, Yue et al. (2012) observed a slightly northward dipping Moho underneath the Qaidam basin. Moreover, the shear wave splitting observation showed that a one-layer anisotropy model with a fast anisotropic direction trending NW-SE in the western and northern NET, is required to fit the model, but two anisotropic layers in the eastern NET (Li et al. 2011). Furthermore, the connections between the LVZ in the crust and upper mantle and the Moho depth and their 


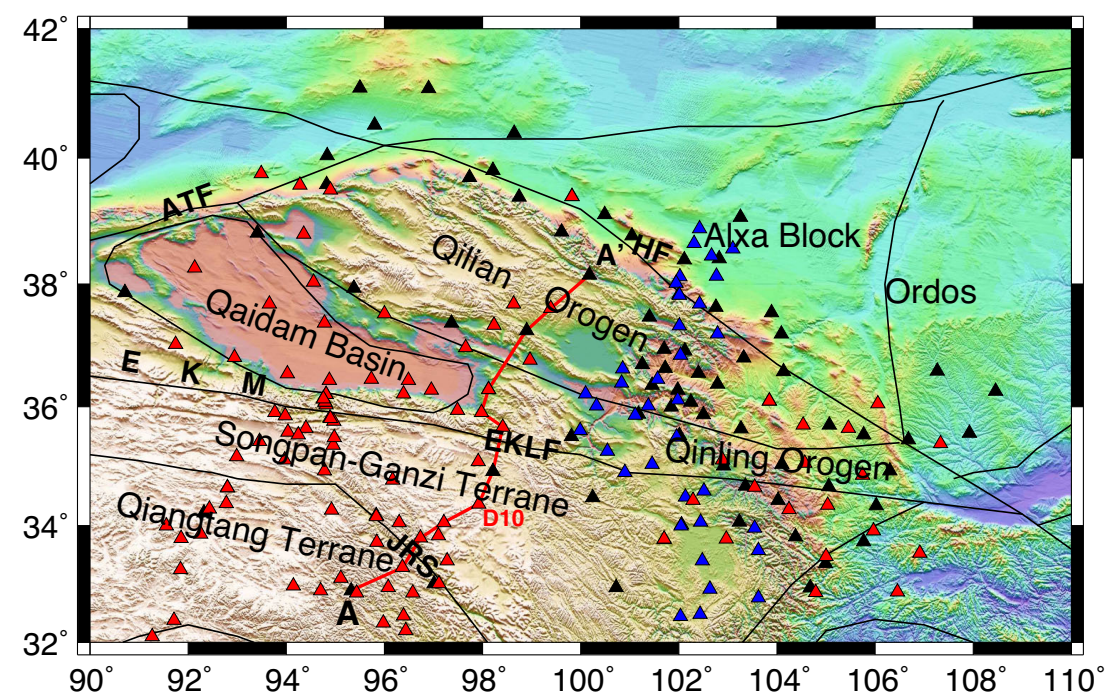

Figure 1. The stations used in this study. Black triangles represent regional stations operated by the China Earthquake Administration (CEA), blue triangles are stations deployed by the Northeastern Tibet Seismic experiment (NETS), red triangles are stations deployed by A Seismic Collaborative Experiment of Northern Tibet (ASCENT), and red line marks the location of profile AA' shown in Fig. 7.
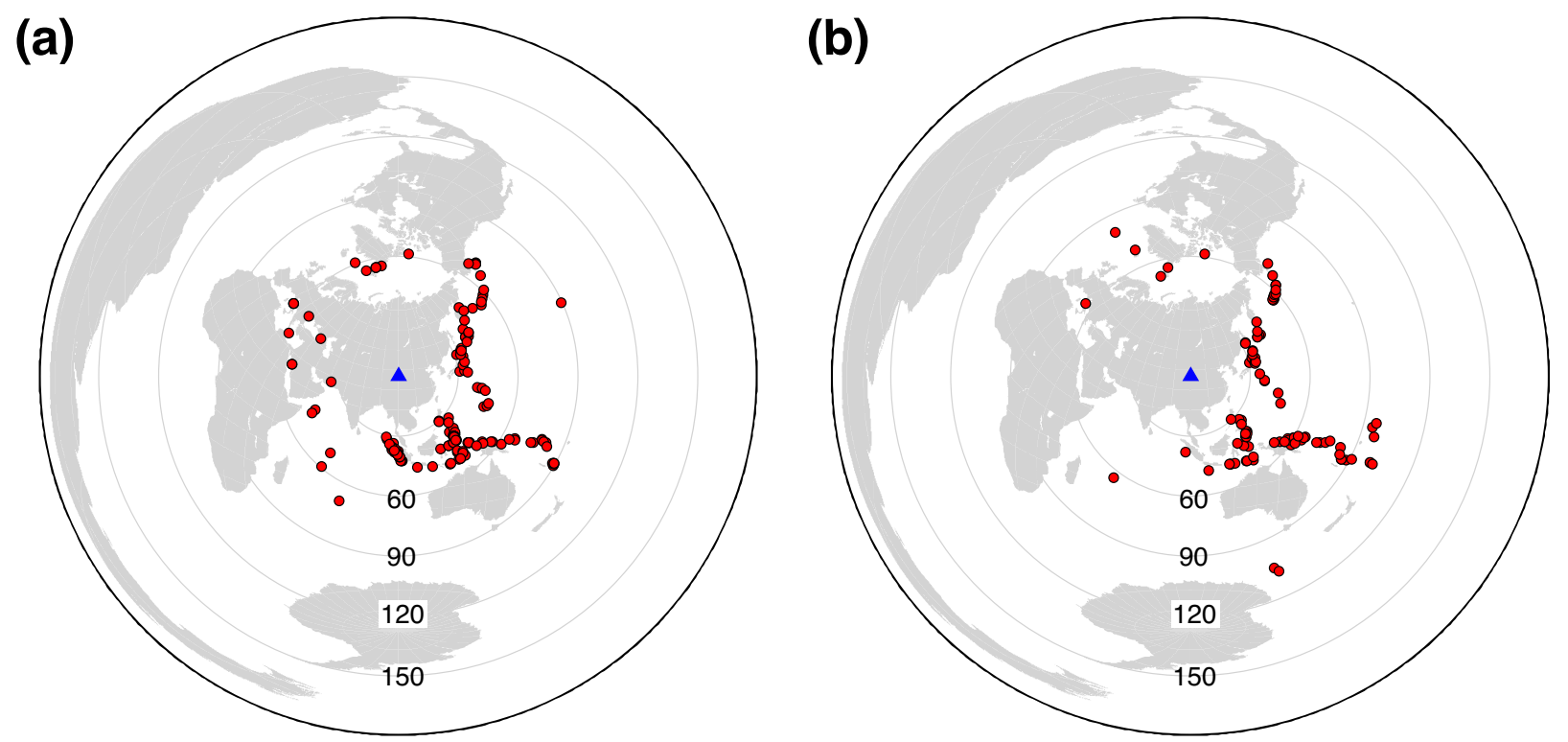

Figure 2. (a) Epicentres of teleseismic events for receiver functions used in this study. (b) Epicentres of teleseismic events for two-plane waves used in this study. Red dots represent earthquakes, and the blue triangle represents the centre of the array.

implications for local tectonics remain open to debate due to limitations of different datasets and/or methods. In this paper, we combine seismic data from different data sources to reveal the high-resolution crust and mantle structure. Specifically, we obtain the velocity structure from the surface down to $150 \mathrm{~km}$ from joint analysis of receiver functions and fundamental-mode Rayleigh wave dispersions.

\section{DATA AND METHODS}

We use a joint inversion technique that combines three types of datasets (receiver functions, phase velocities of fundamental mode Rayleigh wave measured from ambient noise and teleseismic earthquake arrivals) from 223 seismic stations deployed by a number of groups from 2007 to 2010 (Fig. 1) to image the crustal and upper mantle structure in the NET. Since receiver functions are mostly sensitive to velocity discontinuities and surface wave dispersion measurements are more sensitive to volumetric velocity variations, such a joint inversion can significantly improve the resolution compared to those obtained using a single type of data.

847 teleseismic earthquakes with magnitude larger than 5.5 are used for $P$-wave receiver functions analysis (Fig. 2a). A bandpass filter of $0.05-2 \mathrm{~Hz}$ with a Gaussian parameter of 3 is applied. Then receiver functions are calculated with a time-domain iterative deconvolution algorithm (Ligorria \& Ammon 1999). In total 21054 receiver functions at 143 stations are obtained. Finally, the $H-k$ stacking method (Zhu \& Kanamori 2000) is applied to acquire the Moho depth and $V_{\mathrm{p}} / V_{\mathrm{s}}$ ratio (Fig. 3).

Vertical ambient noise data recorded at 211 stations from May 2007 to July 2010 are used to extract short- to intermediate-period surface waves. Phase velocity dispersion curves are measured using automatic frequency time analysis (Ritzwoller \& Levshin 1998). About 3000 high quality Rayleigh wave phase velocity dispersion 

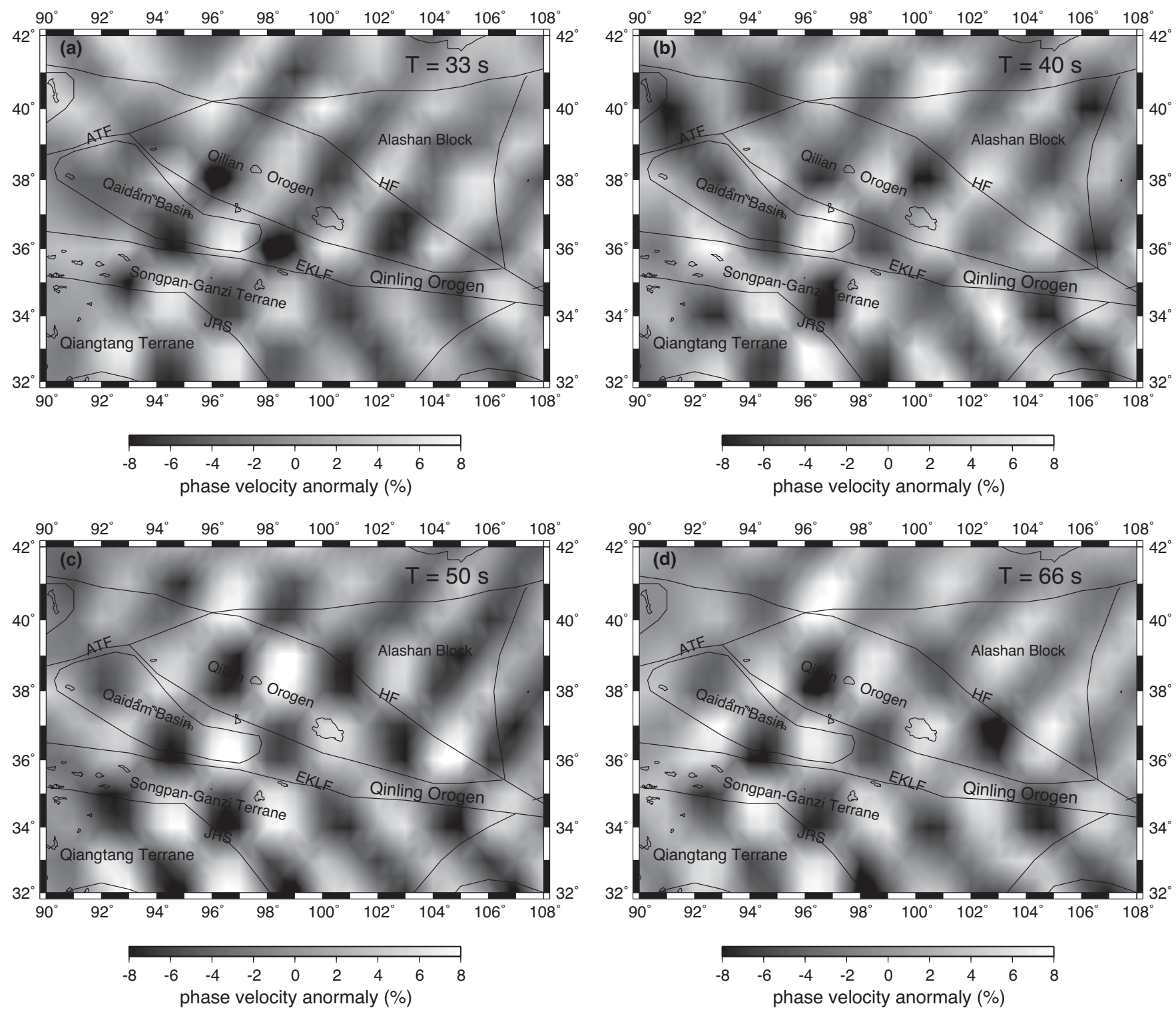

Figure 3. The checkerboard tests of the teleseismic surface waves.

curves in the period range of 10-40 s are extracted. Checkerboard tests show that the estimated lateral resolution is about $0.5^{\circ}$.

Following the data processing procedure given by Yang \& Forsyth (2006a,b), 100 teleseismic events with magnitudes larger than 5.5 and epicentral distances between $30^{\circ}$ and $120^{\circ}$ (Fig. 2b) are selected for two-plane wave tomography. Then, Rayleigh wave dispersions from 25 to $83 \mathrm{~s}$ are extracted. Checkerboard tests show that the lateral resolution with the teleseismic arrivals is about $2^{\circ}$ except the marginal area (Fig. 3). Rayleigh wave dispersion measurements from ambient noise and two-plane wave methods are then combined to generate Rayleigh wave phase velocity maps from 10 to $83 \mathrm{~s}$.

By simultaneously inverting the Rayleigh wave dispersions and receiver functions with the method of Julià et al. (2000), we construct a 3-D shear wave velocity model from the surface down to $160 \mathrm{~km}$ depth. During the joint inversion, the starting model is a simple half space model with a constant shear wave velocity of $4.6 \mathrm{~km} \mathrm{~s}^{-1}$, a $V_{\mathrm{p}} / V_{\mathrm{s}}$ ratio of 1.75 , and a density of $3.3 \mathrm{~kg} \mathrm{~m}^{-3}$. The layer thickness is $1 \mathrm{~km}$ from the surface to the depth of 80 and $5 \mathrm{~km}$ beneath the depth of $80 \mathrm{~km}$. Thus, we did not define the Moho depth in the initial model, but rather rely on the joint inversion of receiver functions and surface wave dispersion to determine the Moho independent of the $H-k$ stacking. Moreover, for the receiver functions used in the joint inversion, we discard the stations with only a few receiver functions $(<4)$. For example, the joint inversion results for the station D10 are illustrated in Fig. 4. As shown in the figure, the Moho discontinuity is clearly identified by the velocity change and the inverted model generally fits the observed data. The crustal thickness obtained from the joint inversion is generally consistent with those obtained from the $H-k$ stacking (Fig. S1).

\section{RESULTS}

The Moho depths estimated from receiver functions are given in Fig. 5(a). The crustal thickness shows an inverse relation with topography, reflecting general isostatic compensation of the topography (Fig. S2). The deepest Moho (at $\sim 65-75 \mathrm{~km}$ depth) in this study area is observed beneath the Songpan-Ganzi and Qiangtang terranes. In the Qaidam basin, however, the Moho becomes 


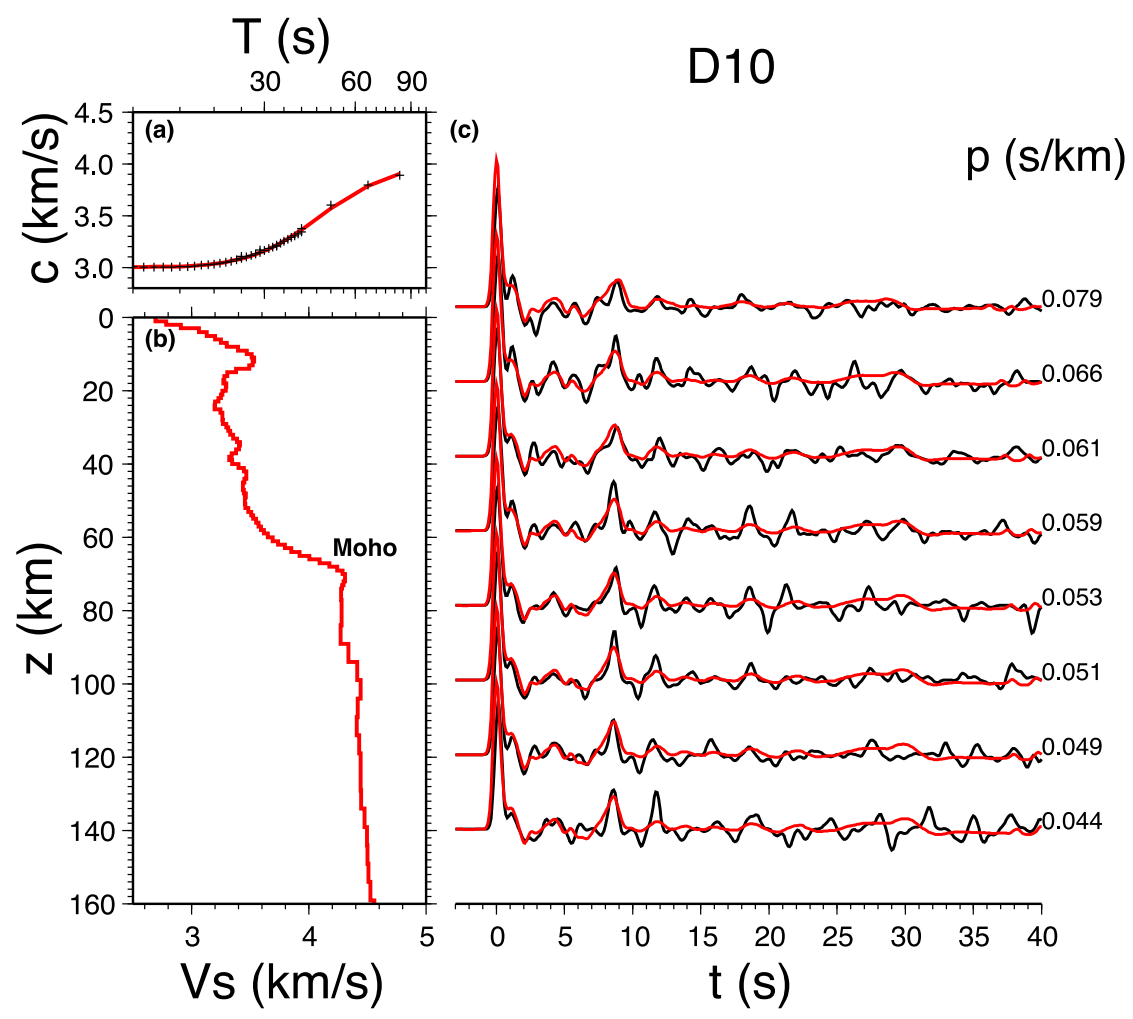

Figure 4. (a) The dispersion curve fitting: black crosses denote observed phase velocities and red lines represent predicted phase velocities. (b) The inverted $S$ wave velocity structure for station D10 located at $32.949^{\circ} \mathrm{N}, 100.727^{\circ} \mathrm{E}$. (c) Receiver function fitting: black and red lines represent observed and predicted receiver functions, respectively. The values to the right of the curves are ray parameters.

shallower to $\sim 50-55 \mathrm{~km}$ depth. The NW Qilian has a relatively deep Moho ( $\sim 60-65 \mathrm{~km}$ depth), but the Moho interface is at $\sim 45-$ $50 \mathrm{~km}$ depth in the southeastern Qilian.

Fig. 5(b) illustrates the variation of the $V_{\mathrm{p}} / V_{\mathrm{s}}$ ratio of the crust across the NET. The $V_{\mathrm{p}} / V_{\mathrm{s}}$ ratios are relatively high with an average value of 1.8 in the Qiangtang terrane and west Songpan-Ganzi terrane, where thickened crusts are observed. In contrast, beneath the NW Qilian orogen, which also has a relative thick crust, the $V_{\mathrm{p}} / V_{\mathrm{s}}$ ratios are much lower, with an average value of 1.73 . The detailed crustal thickness, $V_{\mathrm{p}} / V_{\mathrm{s}}$ ratio and the error of each station are attached in Table $\mathrm{S} 1$ of the supplementary file.

Our inverted $S$ wave velocity results display prominent velocity heterogeneities in the crust and mantle (Figs 6 and S3). As shown in Fig. 6(a), from $20 \mathrm{~km}$ down to $40 \mathrm{~km}$, the Qaidam basin is clearly delineated with high velocity. The Songpan-Ganzi and Qiangtang terranes, however, show extremely low velocity features. Moreover, we observe that the NW Qilian orogen, which has a deeper Moho and higher elevation, exhibits a lower velocity than the southeastern Qilian orogen. In the lower crust (Fig. 6b), the velocity pattern is quite similar to that in the mid-to-lower crust. From 80 to $120 \mathrm{~km}$ depth, the Qilian orogen is characterized by high velocity zones, while the eastern Kunlun fault shows continuous low velocity anomaly from the mid-to-lower crust to the upper mantle. Beneath the Songpan-Ganzi and Qiangtang terranes, the upper mantle has alternating high and low velocities (Fig. 6c), unlike the widespread distribution of the LVZ in the crust above (Fig. 6a). From 120 to $160 \mathrm{~km}$ depth, the Qiangtang and Songpan-Ganzi terranes are obviously delineated with high velocities (Fig. 6d), but the eastern Kunlun fault (east of $98^{\circ} \mathrm{E}$ ) still has low velocities, which are also observed by Liang et al. (2012) using finite frequency traveltime tomography. Moreover, to the north of the eastern Kunlun fault velocities are clearly lower than to the south of the eastern Kunlun fault (Fig. 6d).

\section{DISCUSSIONS}

The NET has experienced complicated crustal deformation during the India and Eurasia continental collision (Yin \& Harrison 2000). The $V_{\mathrm{p}} / V_{\mathrm{s}}$ ratio is associated with the composition of crustal materials. The mafic crustal composition would lead to a high $P$-wave velocity and a high $V_{\mathrm{p}} / V_{\mathrm{s}}$ ratio in an averaged column (Hacker et al. 2000). Mafic crustal rocks usually have a higher Poisson's ratio, hence a higher $V_{\mathrm{p}} / V_{\mathrm{s}}$ value, than felsic rocks (e.g. Pan \& Niu 2011). As the $V_{\mathrm{p}} / V_{\mathrm{s}}$ increases with a rising fluid fraction, partial melting also has great influences on the $V_{\mathrm{p}} / V_{\mathrm{s}}$ (Watanabe 1993). We find the LVZ in the crust of both the NW Qilian orogen and the Songpan-Ganzi terranes. However, the $V_{\mathrm{p}} / V_{\mathrm{s}}$ in the SongpanGanzi and Qiangtang terranes is significantly higher than in the Qilian orogen. The distribution of the high $V_{\mathrm{p}} / V_{\mathrm{s}}$ is generally consistent with the widespread LVZ beneath the Songpan-Ganzi and Qiangtang terranes. The magnetotelluric observations showed that a high conductive layer was observed at $30-40 \mathrm{~km}$ depth beneath the northern Tibet, which was considered as a result of partial melting in the crust (Wei et al. 2001). The presence of extensive Cenozoic potassic magmatism in the Songpan-Ganzi and Qiangtang terranes indicates that the magma is from the upper mantle (Chung et al. 2005). The LVZ and higher $V_{\mathrm{p}} / V_{\mathrm{s}}$ in the crust of the Songpan-Ganzi and Qiangtang terranes may be associated with a more mafic crust and crustal partial melting.

The isolated crustal LVZ in the NW Qilian orogen generally shows higher velocity $(\sim 4-5$ per cent) than that beneath the 

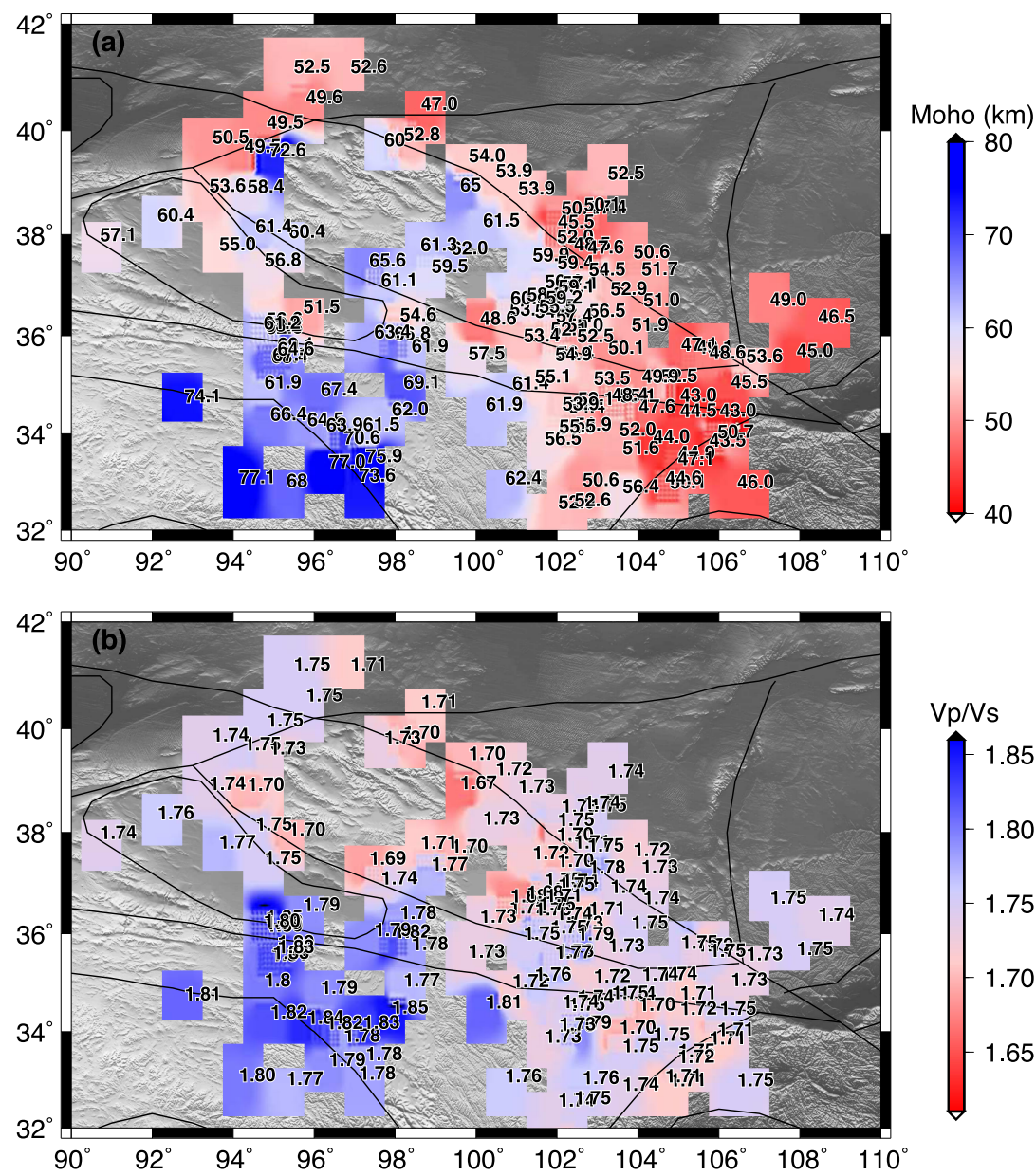

Figure 5. Estimated Moho depth (a) and $V_{\mathrm{p}} / V_{\mathrm{s}}$ ratios (b) from receiver functions.

Songpan-Ganzi and Qiangtang terranes. We also notice that in the NW Qilian orogen the elevation is $\sim 400-500 \mathrm{~m}$ lower and the Moho depth is $\sim 5-10 \mathrm{~km}$ shallower than in the Songpan-Ganzi and Qiangtang terranes. The NET experienced rapid uplift and active NE-SW shortening during the Late-Cenozoic (Chen et al. 2000). The NET could be considered as a growing part of the plateau and the relatively higher velocity in the crustal LVZ in the NW Qilian orogen compared with that of the Songpan-Ganzi and Qiangtang terranes is considered as an indication of an early stage of the LVZ (Bao et al. 2013). Based on zircon U-Pb geochronology and geochemistry study in Xiaoliugou located in the central part of NW Qilian orogen, Zhao et al. (2014) reported that local monzogranite containing radioactive elements may indicate felsic magma in the crust. Therefore, the more felsic crustal composition and possibly less wide-spread presence of crustal melt could explain why the $V_{\mathrm{p}} / V_{\mathrm{s}}$ in this area is not as high as that in the Songpan-Ganzi and Qiangtang terranes.

If the crust channel flow model is the primary mode of the plateau growth in the NET, it would predict a mid-to-lower crust LVZ beneath the Songpan-Ganzi and Qiangtang terranes as well as the adjacent west Qinling and southeastern Qilian orogens, but not the NW Qilian orogen because of the Qaidam basin. In this study, however, we observe the crustal LVZ in both the NW Qilian orogen and the Songpan-Ganzi and Qiangtang terranes where the Moho is deeper than $60 \mathrm{~km}$. Beneath the west Qinling and southeastern Qilian orogens, which have a relatively thin $(\sim 50 \mathrm{~km})$ crust, we do not observe such a crustal LVZ (Figs 5a, b and S3a). These observations indicate that crustal channel flow is not the primary mechanism by which the NET grows.

Previous GPS studies (Zhang et al. 2004) suggest that the rate of shortening between the Qinling orogen and the Songpan-Ganzi terrane is $8.7 \pm 1.8 \mathrm{~mm} \mathrm{yr}^{-1}$ and the GPS velocity field turns to east sharply around $95^{\circ} \mathrm{E}$ to $100^{\circ} \mathrm{E}$ near the eastern Kunlun fault. In this paper, the shear wave velocity structure shows an evident shear wave LVZ that appears not only in the mid-to-lower crust, but also in the upper mantle beneath the eastern Kunlun fault. The resistivity model based on magnetotelluric study (Pape et al. 2012) shows a highly conductive feature from the Moho to $150 \mathrm{~km}$ (Unsworth et al. 2004), which corresponds well with the LVZ in the upper mantle of the western Qiangtang and Songpan-Ganzi terranes and the eastern Kunlun fault in our study. At the depth of $40 \mathrm{~km}$, a temperature of more than $1000^{\circ} \mathrm{C}$ is found in the mid-to-lower crust of the eastern Kunlun fault, Songpan-Ganzi and Qiangtang terranes (Sun et al. 2013). Temperatures greater than adiabatic temperature at $100 \mathrm{~km}$ depth, $1300{ }^{\circ} \mathrm{C}$, are also observed in the eastern Kunlun fault near $100^{\circ} \mathrm{E}$ and the western Qiangtang and Songpan-Ganzi terranes near $93^{\circ} \mathrm{E}$, while those in the surrounding areas are between 1100 and $1300{ }^{\circ} \mathrm{C}$ (An \& Shi 2007). In addition, Li et al. (2008) observed low $P$-wave speed beneath the Songpan-Ganzi, Qiangtang terranes and eastern Kunlun fault at 100-300 km depth. A low Pn velocity belt extending from west to east beneath the Qiangtang and SongpanGanzi terranes and then turning southward is reported by Liang \& Song (2006), who suggested that the consistency between the surfacial geological boundary and rapid velocity change boundary 

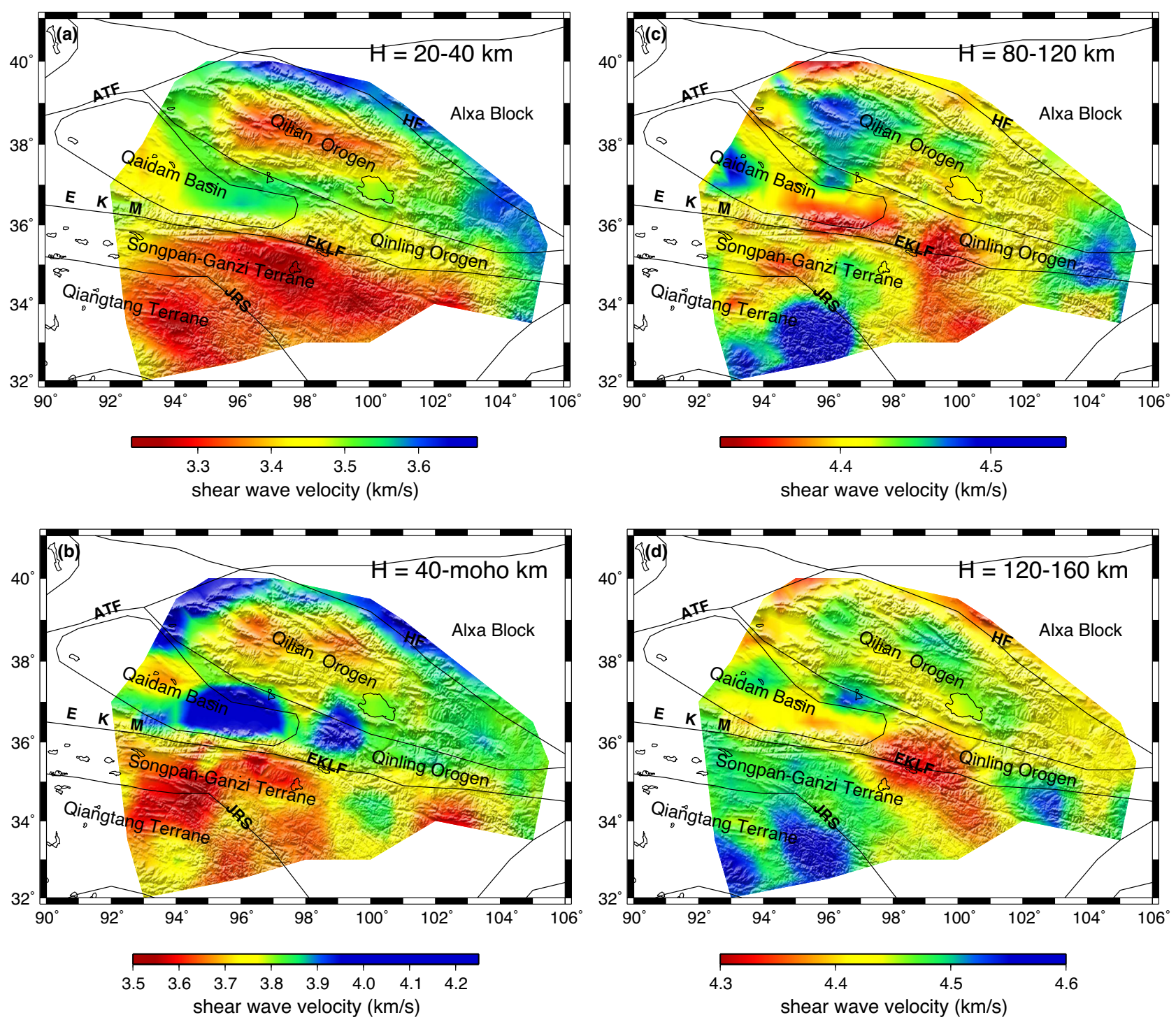

Figure 6. Inverted shear wave velocity from 20 to $40 \mathrm{~km}$ (a), from $40 \mathrm{~km}$ to Moho (b), from 80 to $120 \mathrm{~km}$ (c) and from 120 to $160 \mathrm{~km}$ (d).

in the uppermost mantle may reflect a strong crustal and uppermost mantle coupling in deformation. Surface wave tomography by $\mathrm{Li}$ et al. (2013) also found that at $120 \mathrm{~km}$ depth there is a striking low-velocity anomaly underneath the turning of the eastern Kunlun fault, and they related it to the partial melting due to local mantle upwelling after partial detachment of the lithosphere.

Studies on the mantle transition zone thickness based on receiver functions (Yue et al. 2012) showed that beneath the Lhasa terrane, the mantle transition zone has been thickened $\left(\sim 270 \mathrm{~km}\right.$ at $32^{\circ} \mathrm{N}$, $\left.93^{\circ} \mathrm{E}\right)$, while it becomes much thinner around the Qiangtang terrane $\left(\sim 220 \mathrm{~km}\right.$ at $\left.34^{\circ} \mathrm{N}, 93^{\circ} \mathrm{E}\right)$ and the eastern Kunlun fault $(\sim 240 \mathrm{~km}$ at $35^{\circ} \mathrm{N}, 99^{\circ} \mathrm{E}$ ). They observed a $410-\mathrm{km}$ depression in the northern Tibet and a depressed $660-\mathrm{km}$ discontinuity in the central Tibet, and suggested that the sinking of an oceanic plate in the mantle transition zone may explain the thickness variation of the mantle transition zone. However, depending on the strength and duration of small-scale mantle convection, such a mechanism may or may completely erode and remove the mantle lithosphere above the regions of mantle upwelling. In our study, the continuous LVZs from the crust to as low as $4.1-4.2 \mathrm{~km} \mathrm{~s}^{-1}$ in the upper mantle beneath the eastern Kunlun fault, the Songpan-Ganzi and part of the Qiangtang terrane suggest very little remaining mantle lithosphere in those areas (Fig. 7). The scenario is most consistent with the detachment of the lithosphere root that has completely or near completely removed the mantle lithosphere and the induced local mantle upwelling after the delamination of the lithosphere. The thickened crust or lithosphere in the NET could lead to a gravitationally unstable lithosphere, for which detachment/delamination is possible. Once delamination occurs, the induced counter flow would cause mantle upwelling and associated partial melting. This interpretation is supported by the distribution pattern of Cenozoic granites in northern Tibet which spreads from the centre of the plateau to the surrounding, indicating that the magma may originate from the local deep detachment (Mo et al. 2005).

\section{CONCLUSIONS}

In this study, we show a joint inversion of receiver functions and Rayleigh wave dispersion measurements derived from teleseismic earthquakes and ambient noise data during 2007-2010 recorded by 223 stations. The main conclusions are: 

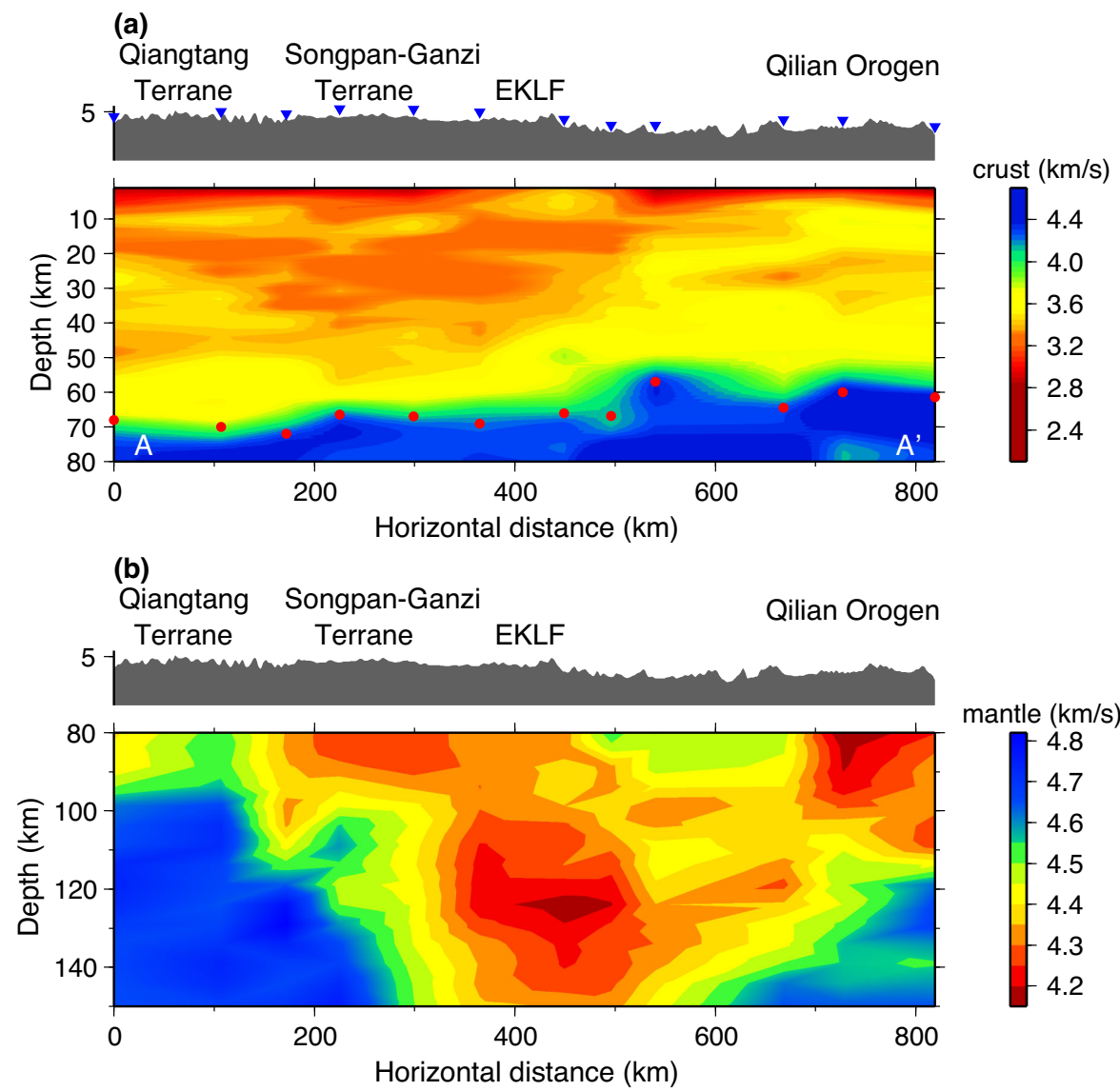

Figure 7. The shear wave velocity structure along the profile $\mathrm{AA}^{\prime}$ shown in Fig. 1. (a) Shear wave velocity in the top $80 \mathrm{~km}$ depth, showing mainly crust velocity variations. Inverted blue triangles represent stations. Red dots are the Moho depth from receiver functions. (b) Shear wave velocity in the upper mantle.

(1) A 3-D shear wave velocity model shows that the eastern Kunlun fault and the west Qiangtang and Songpan-Ganzi terranes are featured by a continuous LVZ from the mid-to-lower crust to $160 \mathrm{~km}$. This feature, along with other geological and geophysical evidence, is consistent with the induced localized mantle upwelling after the delamination of the lithosphere, an observation providing new constraints for the deformation mechanism of the crust and upper mantle of the NET.

(2) The presence of a local crustal LVZ in the NW Qilian orogen, which has a relatively thick Moho $(>60 \mathrm{~km})$, suggests that the crustal LVZ is more likely related to crust thickening. No crustal LVZ is found under the west Qinling and southeastern Qilian orogens, which are featured with a relatively thin $(\sim 50 \mathrm{~km})$ crust. These observations indicate that crustal channel flow is unlikely the primary mode by which the NET grows.

\section{ACKNOWLEDGEMENTS}

We thank the PIs and team members of the NETS and ASCENT experiments for gathering those data in the NET and also the CEA for offering the waveform data. Valuable comments by two anonymous reviewers and the editor are greatly appreciated. This work was funded by National Science Foundation of China under Grant Nos 41174050, 40804007, the U.S. National Science Foundation under Grant No. 0738779, and the Fundamental Research Funds for the Central Universities.

\section{REFERENCES}

An, M. \& Shi, Y., 2007. Three-dimensional thermal structure of the Chinese continental crust and upper mantle, Sci. China Ser. D-Earth Sci., 50(10), $1141-1451$

Bao, X., Song, X., Xu, M., Wang, L., Sun, X., Mi, N., Yu, D. \& Li, H., 2013. Crust and upper mantle structure of the North China Craton and the NE Tibetan Plateau and its tectonic implications, Earth planet. Sci. Lett., 369-370, 129-137.

Bai, D. et al., 2010. Crustal deformation of the eastern Tibetan plateau revealed by magnetotelluric imaging, Nat. Geosci., 3, 358-362.

Chen, Z. et al., 2000. Global Positioning System measurements from eastern Tibet and their implications for India/Eurasia inter-continental deformation, J. geophys. Res., 105, 16 215-16 227.

Chung, S.-L. et al., 2005. Tibetan tectonic evolution inferred from spatial and temporal variations in post-collisional magmatism, Earth Sci. Rev., 68, 173-196.

Clark, M.K. \& Royden, L.H., 2000. Topographic ooze: building the eastern margin of Tibet by lower crustal flow, Geology, 28, 703-706.

Hacker, B.R., Gnos, E., Ratschbacher, L., Grove, M., McWilliams, M., Sobolev, S.V., Wan, J. \& Zhenhan, W., 2000. Hot and dry deep crustal xenoliths from Tibet, Science, 287, 2463-2466.

Jiang, C., Yang, Y. \& Zheng, Y., 2014. Penetration of mid-crustal low velocity zone across the Kunlun Fault in the NE Tibetan Plateau revealed by ambient noise tomography, Earth planet. Sci. Lett., 406, 81-92.

Julià, J., Ammon, C.J., Herrmann, R.B. \& Correig, A.M., 2000. Joint inversion of receiver functions and surface-wave dispersion observations, Geophys. J. Int., 143, 99-112.

Kind, R. et al., 2002. Seismic images of crust and upper mantle beneath Tibet: evidence for Eurasian plate subduction, Science, 298(5596), 12191221. 
Kirby, E., Harkins, N., Wang, E., Shi, X., Fan, C. \& Burbank, D., 2007. Slip rate gradients along the eastern Kunlun fault, Tectonics, 26, TC2010, doi:10.1029/2006TC002033.

Li, C., van der Hilst, R.D., Meltzer, A.S. \& Engdahl, R., 2008. Subduction of the Indian lithosphere beneath the Tibetan Plateau and Burma, Earth planet. Sci. Lett., 274, 157-168.

Li, H., Su, W., Wang, C.-Y. \& Huang, Z., 2009. Ambient noise Rayleigh wave tomography in western Sichuan and eastern Tibet, Earth planet. Sci. Lett., 282, 201-211.

Li, Y., Wu, Q., Zhang, F., Feng, Q. \& Zhang, R., 2011. Seismic anisotropy of the Northeastern Tibetan Plateau from shear wave splitting analysis, Earth planet. Sci. Lett., 304, 147-157.

Li, L., Li, A., Shen, Y., Sandvol, E.A., Shi, D., Li, H. \& Li, X., 2013. Shear wave structure in the northeastern Tibetan Plateau from Rayleigh wave tomography, J. geophys. Res.: Solid Earth, 118, 4170-4183.

Li, H., Shen, Y., Huang, Z., Li, X., Gong, M., Shi, D., Sandvol, E. \& Li, A., 2014. The distribution of the mid-to-lower crustal low-velocity zone beneath the northeastern Tibetan Plateau revealed from ambient noise tomography, J. geophys. Res.: Solid Earth, 119, 1954-1970.

Liang, C. \& Song, X., 2006. A low velocity belt beneath northern and eastern Tibetan Plateau from Pn tomography, Geophys. Res. Lett., 33, L22306, doi:10.1029/2006GL027926.

Liang, X., Sandvol, E., Chen, Y.J., Hearn, T., Ni, J., Klemperer, S., Shen, Y. \& Tilmann, F., 2012. A complex Tibetan upper mantle: a fragmented Indian slab and no south-verging subduction of Eurasian lithosphere, Earth planet. Sci. Lett., 333-334, 101-111.

Ligorria, J.P. \& Ammon, C.J., 1999. Iterative deconvolution and receiverfunction estimation, Bull. seism. Soc. Am., 89(5), 1395-1400.

Liu, Q.Y. et al., 2014. Eastward expansion of the Tibetan plateau by crustal flow and strain partitioning across faults, Nat. Geosci., 7, 361-365.

Mo, X., Dong, G., Zhao, Z., Zhou, S., Wang, L., Qiu, R. \& Zhang, F., 2005. Spatial and temporal distribution and characteristics of Granitoids in the Gangdese, Tibet and implication for crustal growth and evolution, Geol. J. China Univ., 11(3), 281-290.

Pan, S. \& Niu, F., 2011. Large contrasts in crustal structure and composition between the Ordos plateau and the NE Tibetan plateau from receiver function analysis, Earth planet. Sci. Lett., 303, 291-298.

Pape, F., Jones, A.G., Vozar, J. \& Wei, W., 2012. Penetration of crustal melt beyond the Kunlun Fault into northern Tibet, Nat. Geosci., 5, 330-335.

Ritzwoller, M.H. \& Levshin, A.L., 1998. Eurasian surface wave tomography: group velocities, J. geophys. Res., 103, 4839-4878.

Royden, L.H., Burchfiel, B.C., King, R.W., Wang, E., Chen, Z., Shen, F. \& Liu, Y., 1997. Surface deformation and lower crustal flow in eastern Tibet, Science, 276, 788-790.

Sun, Y., Dong, S., Zhang, H., Li, H. \& Shi, Y., 2013. 3D thermal structure of the continental lithosphere beneath China and adjacent regions, J. Asian Earth Sci., 62, 697-704.

Tapponnier, P., Zhiqin, X., Roger, F., Meyer, B., Arnaud, N., Wittlinger, G. \& Jingsui, Y., 2001. Oblique stepwise rise and growth of the Tibet plateau, Science, 294, 1671-1677.

Unsworth, M. et al., 2004. Crustal and upper mantle structure of northern Tibet imaged with magnetotelluric data, J. geophys. Res., 109, B02403, doi:10.1029/2002JB002305.
Watanabe, T., 1993. Effects of water and melt on seismic velocities and their application to characterization of seismic reflectors, Geophys. Res. Lett., 20(24), 2933-2936.

Wei, W. et al., 2001. Detection of widespread fluids in the Tibetan crust by magnetotelluric studies, Science, 292, 716-718.

Yang, Y. \& Forsyth, D.W., 2006a. Regional tomographic inversion of the amplitude and phase of Rayleigh waves with 2-D sensitivity kernels, Geophys. J. Int., 166(3), 1148-1160.

Yang, Y. \& Forsyth, D.W., 2006b. Rayleigh wave phase velocities, smallscale convection, and azimuthal anisotropy beneath southern California, J. geophys. Res., 111, B07306, doi:10.1029/2005JB004180.

Yao, H., Beghein, C. \& van der Hilst, R.D., 2008. Surface-wave array tomography in SE Tibet from ambient seismic noise and two-station analysis: II-crustal and upper-mantle structure. Geophys. J. Int., 173, 205-219.

Yin, A. \& Harrison, M., 2000. Geological evolution of the HimalayanTibetan orogen, Annu. Rev. Earth planet. Sci., 28, 211-280.

Yue, H. et al., 2012. Lithospheric and upper mantle structure of the northeastern Tibetan Plateau, J. geophys. Res., 117, B04303, doi: 10.1029/2011JB008545.

Zhang, P.-Z. et al., 2004. Continuous deformation of the Tibetan plateau from global positioning system data, Geology, 32(9), 809-812.

Zhao, X., Zhang, Z., Liu, M., Li, Y. \& Guo, S., 2014. Zircon U-Pb geochronology, geochemistry and petrogenesis of the granites from the Xiaoliugou deposit in the western of the North Qilian, Acta Petrologica Sinica, 30(1), 16-34.

Zhu, L. \& Kanamori, H., 2000. Moho depth variation in southern California from teleseismic receiver functions, J. geophys. Res., 105(B2), 29692980 .

\section{SUPPORTING INFORMATION}

Additional Supporting Information may be found in the online version of this paper:

Figure S1. The H-k stacking and the joint inversion results of the three stations: the Songpanganzi terrane (a), Qiangtang terrane (b) and Qilian orogen (c).

Figure S2. The crustal thickness generally shows an inverse relation with topography. With the increase of topography, the Moho deepens.

Figure S3. Shear wave structure from surface down to $20 \mathrm{~km} \mathrm{(a),}$ from the Moho down to $80 \mathrm{~km}$ (b).

Table S1. The crustal thickness, the $V_{\mathrm{p}} / V_{\mathrm{s}}$ ratio, and the error of each station in this study.

(http://gji.oxfordjournals.org/lookup/suppl/doi:10.1093/gji/ggv469 /-/DC1).

Please note: Oxford University Press is not responsible for the content or functionality of any supporting materials supplied by the authors. Any queries (other than missing material) should be directed to the corresponding author for the paper. 